\title{
Number of living organ donors doubled in 7 years
}

For the last 3 years, the number of living organ donors has exceeded the number of deceased $\vec{r}$ donors, according to the Canadian Organ Replacement Registry of the Canadian Institute for Health Information. The $\approx$ number of living donors doubled from 1994 to 2001 but has $\ddot{ت}$ since levelled out to an overall rate of 13.8 per 1 million Cana-

\section{Organ Donors: 2003 Rate per million population}

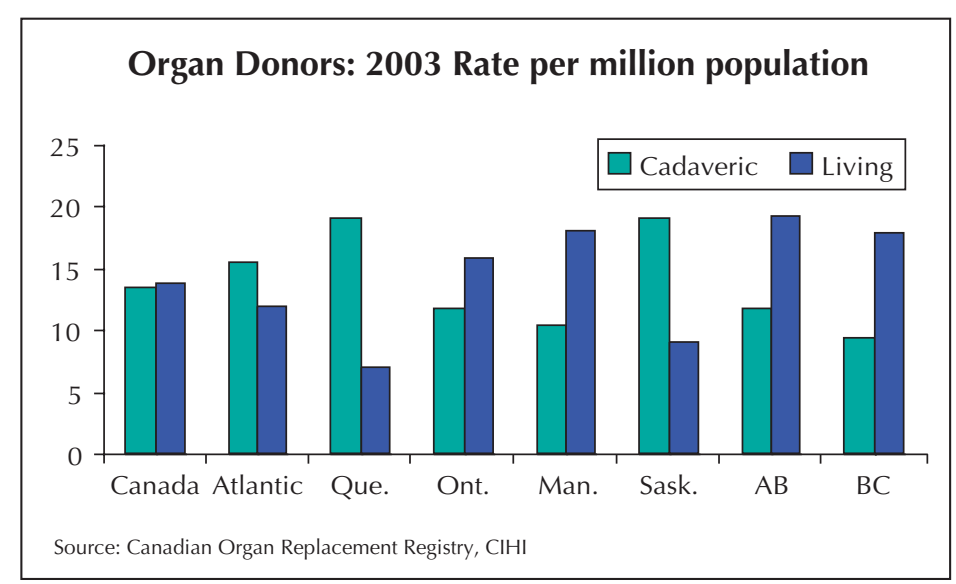

dians. The highest living organ donor rate occurred in Alberta, where there were 19.3 living organ donors per 1 million people. Quebec had the lowest rate at 6.9 per 1 million population.

The 2003 overall cadaveric donor rate in Canada was 13.5 per million population, a rate that has remained steady over the last decade. The rate of ca- daveric organ donors is highest in Quebec and Saskatchewan at 19.0 per million population and lowest in British Columbia with a rate of 9.4 .

Almost three quarters (73\%) of the patients on organ waiting lists required kidney transplants. Last year, 250 patients died while waiting for new organs: 82 were waiting for a kidney, 100 for a liver, 30 for a heart, 26 for a lung and 12 for other organs.

The total number of transplants rose from 1473 in 1994 to 1804 in 2003 , but the rate of heart transplants has remained between 4.9 and 6.2 per million population over the past decade.

There has, however, been an increase in the number of lung and heart-lung transplants, which averaged 127 during the last 4 years compared to 86 during the previous 4 years. - Lynda Buske, Associate Director of Research, CMA

\section{Pharmaceutical Industry}

\section{Stockholders protest Pfizer's drug prices}

A US coalition of 275 faithbased organizations that control an estimated $\$ 100$ billion in assets is targeting the pricing practices of a number of drug companies. The coalition previously led antiapartheid shareholder movements.

Charging that high drug prices are a "social justice problem," the Interfaith Center on Corporate Responsibility (ICCR) submitted a proposal to "increase access to Pfizer products" at Pfizer's April 22 annual meeting. Although the proposal was defeated, it did receive $5 \%$ of the vote, surpassing the $3 \%$ required by the Securities $\approx$ and Exchange Commission to allow a proposal to be reintroduced the following year.

"This alerts the rest of the shareholders that this is a concern," said Margaret Weber, coordinator of corporate responsibility for the Adrian Dominican
Sisters, an ICCR member.

In its proposal, ICCR said price increases accounted for $1 / 3$ of the increased spending on prescription drugs in 2001. The group's resolution sought to have Pfizer "contain the price of increases of its most-prescribed drug to levels equal to or below the annual rate of inflation."

Pfizer board members unanimously opposed the resolution. Dr. Henry A. McKinnell, Jr., Chairman of Pfizer, who was paid $\$ 7$ million in 2003 plus stock options and long-term payouts worth roughly $\$ 39$ million, said groups like ICCR should focus on "disease costs" instead of "drug costs."

"But if the cost of the cure makes it inaccessible then the cost of the disease only increases," noted Weber.

The ICCR is also concerned by what it views as undue politi- cal influence exerted by the pharmaceutical industry. According to the Center for Responsive Politics, a US political watchdog organization, Pfizer gave $\$ 1.8$ million in 2002 in soft money and Political Action Committee funds - an increase of $600 \%$ from 1992 .

ICCR recently backed a proposal demanding a complete accounting of money given to politicians. It stated: "Our company should be using its resources to win in the marketplace through superior products ... not because it has superior access to political leaders."

The proposal, unanimously opposed by Pfizer's board, won $10 \%$ of the vote. Pfizer agreed to make the requested disclosures. Pfizer did not respond to interview requests for this article. - Jeanne Lenzer, Kingston, New York 